\title{
Soils need to be considered when assessing the impacts of land-use change on carbon sequestration
}

\author{
Sandra Duarte-Guardia', Pablo L. Peri ${ }^{1,2}$, Nils Borchard ${ }^{3}$ and Brenton Ladd $\mathbb{D}^{4 \star}$ \\ ARISING FROM A. Marques et al. Nature Ecology \& Evolution https://doi.org/10.1038/s41559-019-0824-3 (2019)
}

In a recent analysis of the effects of land-use change (LUC) on carbon $(\mathrm{C})$ sequestration and biodiversity, Marques et al. ${ }^{1}$ conclude that the impacts of forestry on $\mathrm{C}$ sequestration are probably much larger than for other types of land-use transition. This conclusion, and the policy recommendations that flow from it, are based solely on considerations of aboveground biomass or (more specifically) "harvest volumes and typical rotation times for managed forests". If instead soils and soil $\mathrm{C}$ are considered, then a completely different set of conclusions and policy recommendations would have emerged.

The effects of LUC on aboveground $\mathrm{C}$ and net $\mathrm{C}$ sequestration are transient ${ }^{2}$. Net ecosystem $C$ sequestration varies strongly with stand age, as is shown for recovering forests, which capture more $\mathrm{C}$ at young stand ages than mature forests (the land-use category that stores the largest amount of $\mathrm{C}$ in aboveground biomass) ${ }^{3}$. In forestry operations, foresters can practice techniques such as selective logging and/or take care to ensure that tree falls do not damage non-target trees, which can minimize impacts on carbon sequestration ${ }^{4}$. But a more important oversight by Marques et al. ${ }^{1}$ was the failure to consider soil organic $C$, which is essential for the delivery of soil-based ecosystem services, but is also vulnerable to LUC ${ }^{5}$. Soils hold more $\mathrm{C}$ than the vegetation and the atmosphere combined ${ }^{6}$. The first $3 \mathrm{~m}$ of the soil profile may contain up to $2,344 \mathrm{PgC}$ versus $600 \mathrm{PgC}$ in aboveground plant biomass ${ }^{7}$. The impacts of LUC on soil C stocks have been widely analysed at both local and global scales. Early ${ }^{5}$, as well as more recent ${ }^{8}$, meta-analyses have demonstrated that the transition to cropland results in much greater losses of soil $\mathrm{C}$ than the transition to forestry.

When the largest and most important terrestrial $\mathrm{C}$ reservoir is considered, a completely different picture emerges to the conclusions of Marques et al. ${ }^{1}$ : a transition to industrial-scale cropping emerges as the LUC that leads to most $\mathrm{C}$ loss. The need to focus on soils and soil C is difficult to overstate. Soils and soil C are critically important providers of ecosystem services ${ }^{9}$ and recovering soil $\mathrm{C}$ is a difficult process that may take decades to millennia. It is even possible that in some cases soil $\mathrm{C}$ levels will never recover to levels observed before $\mathrm{LUC}^{10}$. While this type of economic and policy analysis is urgently needed, future analyses need to include soil C.
Received: 2 April 2019; Accepted: 4 October 2019;

Published online: 4 November 2019

\section{References}

1. Marques, A. et al. Increasing impacts of land use on biodiversity and carbon sequestration driven by population and economic growth. Nat. Ecol. Evol. 3, 628-637 (2019).

2. Stuart Chapin, F. III, Matson, P. A. \& Vitousek, P. M. Principles of Terrestrial Ecosystem Ecology (Springer, 2012).

3. Pregitzer, K. S. \& Euskirchen, E. S. Carbon cycling and storage in world forests: biome patterns related to forest age. Glob. Change Biol. 10, 2052-2077 (2004).

4. Gaveau, D. L. A. et al. Reconciling forest conservation and logging in Indonesian Borneo. PLoS ONE 8, e69887 (2013).

5. Guo, L. B. \& Gifford, R. M. Soil carbon stocks and land use change: a meta analysis. Glob. Change Biol. 8, 345-360 (2002).

6. Duarte, S. et al. Better estimates of soil carbon from geographical data: a revised global approach. Mitig. Adapt. Strateg. Glob. Change 24, 1-18 (2018).

7. Jobbagy, E. G. \& Jackson, R. B. The vertical distribution of soil organic carbon and its relation to climate and vegetation. Ecol. Appl. 10, 423-436 (2000).

8. Deng, L., Zhu, G., Tang, Z. \& Shangguan, Z. Global patterns of the effects of land-use changes on soil carbon stocks. Glob. Ecol. Conserv. 5, 127-138 (2016).

9. Peri, P. L. et al. Soil carbon is a useful surrogate for conservation planning in developing nations. Sci. Rep. 9, 3905 (2019).

10. Lal, R. Soil carbon sequestration impacts on global climate change and food security. Science 304, 1623-1627 (2004).

\section{Author contributions}

S.D.-G. and B.L. wrote the first draft, P.L.P. and N.B. reviewed and edited the manuscript.

\section{Competing interests}

The authors declare no competing interests.

\section{Additional information}

Correspondence and requests for materials should be addressed to B.L.

Reprints and permissions information is available at www.nature.com/reprints.

Publisher's note Springer Nature remains neutral with regard to jurisdictional claims in published maps and institutional affiliations.

(C) The Author(s), under exclusive licence to Springer Nature Limited 2019

\footnotetext{
"Universidad Nacional de la Patagonia Austral-CONICET, Río Gallegos, Argentina. ${ }^{2}$ Instituto Nacional de Tecnología Agropecuaria, Río Gallegos, Argentina. ${ }^{3}$ Plant Production, Natural Resources Institute Finland (Luke), Helsinki, Finland. ${ }^{4}$ Escuela de Agroforestería, Universidad Científica del Sur, Lima, Peru. *e-mail: bladd@cientifica.edu.pe
} 